Show simple item record

\title{
Response of promiscuous-nodulating soybean (Glycine max L. Merr.) genotypes to Bradyrhizobium inoculation at three field sites in Mozambique
}

\begin{tabular}{|c|c|c|}
\hline dc.contributor.author & Gyogluu, C. & \\
\hline dc.contributor.author & Boahen, S.K. & \\
\hline dc.contributor.author & Dakora, F.D. & \\
\hline dc.date.accessioned & 2016-07-07T13:45:53Z & \\
\hline dc.date.available & 2016-07-07T13:45:53Z & \\
\hline dc.date.issued & 2016-06 & \\
\hline dc.identifier.citation & $\begin{array}{l}\text { Gyogluu, C., Boahen, S.K. \& Dakora, F.D. (2016). Response of promiscuous-nodulating soybean (Glycine max L. Merr.) genotypes to } \\
\text { Bradyrhizobium inoculation at three field sites in Mozambique. Symbiosis, } 69(2), 81-88\end{array}$ & en_US \\
\hline dc.identifier.issn & 0334-5114 & \\
\hline dc.identifier.uri & http://hdl.handle.net/10568/76000 & \\
\hline dc.description & Published Online: 27 January, 2016 & en_US \\
\hline dc.description.abstract & $\begin{array}{l}\text { Soybean cultivation in Mozambique is dominated by smallholder farmers who use little or no inputs such as bacterial inoculants, often resulting } \\
\text { in low yields. This study assessed the ability of TGx and non-TGx soybean genotypes to nodulate with native rhizobia in Mozambican soils, and } \\
\text { evaluated the yield and symbiotic response of TGx and non-TGx soybean to inoculation with Bradyrhizobium japonicum strain WB74 at three } \\
\text { IITA experimental sites in Mozambique. The data revealed significant inoculation, location and genotypic effects. Both TGx and non-TGx } \\
\text { soybean genotypes showed effective nodulation in Bradyrhizobium-inoculated and uninoculated field plots. Inoculant applicaion increased plant } \\
\text { growth by } 32 \%, \% \mathrm{~N} \text { by } 18 \%, \mathrm{~N} \text { content by } 45 \% \text {, } \% \text { Ndfa by } 11 \% \text {, fixed-N by } 64 \% \text {, and grain yield by } 12 \% \text { when compared to uninoculated } \\
\text { control. Symbiotically, the soybean genotypes performed better at Ruace than at Nampula, and poorly at Mutequelesse. Genotypes TGx1910- } \\
14 \mathrm{~F}, 427 / 5 / 7, \mathrm{TGx} 1937-1 \mathrm{~F} \text { and Solitaire accumulated the most biomass at Ruace and Nampula when compared to Mutequelesse, and } \\
\text { individually contributed over } 200 \mathrm{~kg} \text { N.ha- } 1 \text { during the cropping season. However, grain yield was much higher at Nampula than at Ruace and } \\
\text { Mutequelesse. Independent of the location, four soybean genotypes produced similar amounts of grain yield in inoculated and uninoculated plots. } \\
\text { Whether with or without inoculation, Solitaire and TGx1908-8F each produced about } 2.0 \text { t.ha- } 1 \text { of grain, while TGx } 1910-14 \mathrm{~F} \text { and TGx1937-1F } \\
\text { yielded between } 1.5 \text { and } 1.7 \text { tha- } 1 \text {. These four varieties were identified as the best for use by resource-poor farmers in Mozambique, while } \\
\text { genotype } 427 / 5 / 7 \text {, which produced about } 2.4 \text { t.ha- } 1 \text { of grain with inoculation, was seen as ideal for well-resourced farmers. }\end{array}$ & en_US \\
\hline dc.format.extent & $81-88$ & en_US \\
\hline dc.language.iso & en & en_US \\
\hline dc.source & Symbiosis & en_US \\
\hline dc.subject & BRADYRHIZOBIUM JAPONICUM & en_US \\
\hline dc.subject & NITROGEN FIXATION & en_US \\
\hline dc.subject & MOZAMBIQUE & en_US \\
\hline dc.subject & GRAIN LEGUMES & en_US \\
\hline dc.subject & SOYBEANS & en_US \\
\hline dc.title & Response of promiscuous-nodulating soybean (Glycine max L. Merr.) genotypes to Bradyrhizobium inoculation at three field sites in Mozambique & en_US \\
\hline dc.description.version & Peer Review & en_US \\
\hline dc.type & Journal Article & en_US \\
\hline cg.authorship.types & CGIAR and developing country institute & en_US \\
\hline cg.subject.iita & GRAIN LEGUMES & en_US \\
\hline cg.subject.iita & SOYBEAN & en_US \\
\hline cg.identifier.status & Limited Access & en_US \\
\hline cg.contributor.affiliation & Tshwane University of Technology & en_US \\
\hline cg.contributor.affiliation & International Institute of Tropical Agriculture & en_US \\
\hline cg.targetaudience & SCIENTISTS & en_US \\
\hline cg.fulltextstatus & Formally Published & en_US \\
\hline cg.identifier.doi & https://dx.doi.org/10.1007/s13199-015-0376-5 & en_US \\
\hline
\end{tabular}




cg.isijournal
cg.coverage.region
cg.coverage.region
cg.coverage.country

\section{Files in this item}

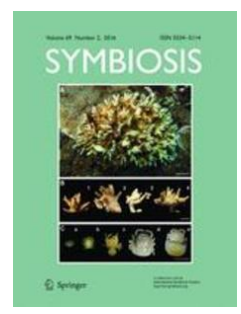

Name:

Symbiosis.jpg

Size:

$6.849 \mathrm{~Kb}$

Format:

JPEG image

View/Open

This item appears in the following Collection(s)

- IITA Journal Articles [834]

Show simple item record

Show Statistical Information 